\title{
Host Gall Size and Temperature Influence Voltinism in an Exotic Parasitoid
}

\author{
Martin Aguirrebengoa*, María Eva Wong, Juan Ramón Boyero and Javier Quinto \\ Laboratorio de Entomología Agrícola, Centro IFAPA de Málaga, Instituto de Investigación y Formación Agraria, Pesquera, \\ Alimentaria y de la Producción Ecológica, Málaga, Spain
}

OPEN ACCESS

Edited by:

Makoto Tokuda,

Saga University, Japan

Reviewed by:

Thomas Wassmer,

Siena Heights University,

United States

Lynne K. Rieske-Kinney,

University of Kentucky, United States

*Correspondence:

Martin Aguirrebengoa

martin.aguirrebengoa@

juntadeandalucia.es

Specialty section:

This article was submitted to Behavioral and Evolutionary Ecology,

a section of the journal

Frontiers in Ecology and Evolution

Received: 27 September 2021 Accepted: 03 February 2022

Published: 24 February 2022

Citation:

Aguirrebengoa $M$, Wong ME Boyero JR and Quinto J (2022) Host Gall Size and Temperature Influence Voltinism in an Exotic Parasitoid. Front. Ecol. Evol. 10:784111. doi: 10.3389/fevo.2022.784111
Insect phenology is highly temperature-dependent. Higher temperatures can lead to earlier emergence and lengthening of the active period, which enable many insect groups to complete more generations. Studies on the effects of climate change on insect populations are providing concerning evidence supporting this relationship. These kind of shifts in phenology and voltinism also occur in agricultural and forest insect pests and their natural enemies, with potential implications for biological control. The consequences derived from changing temperature regimes on tritrophic interactions remain poorly studied, particularly in gall-inducing insects and their parasitoids. Here we detail the occurrence of bivoltinism in the exotic parasitoid Torymus sinensis, previously categorized as univoltine, a widely introduced species to fight against the invasive Asian chestnut gall wasp Dryocosmus kuriphilus wherever this pest spread. This plasticity in voltinism has been observed in the southernmost European distribution of $D$. kuriphilus, and appears to be mediated by both temperature and gall traits, namely size or the number of gall chambers. Bivoltinism was most common at annual mean temperatures around $13.5^{\circ} \mathrm{C}$ and in galls with more chambers. Through this work, we intend to unravel the factors behind this phenomenon and discern the possible consequences on host-parasitoid interactions.

Keywords: biological control, Castanea, climate change, Dryocosmus kuriphilus, insect life-cycle, insect phenology, Torymus sinensis, phenotypic plasticity

\section{INTRODUCTION}

Temperature is one of the main drivers of insect phenology (Gutiérrez and Wilson, 2021). Changing temperatures can foster diverse effects on insect phenology, and main responses are driven by phenotypic plasticity and evolutionary changes (Forrest, 2016; Marshall et al., 2020; Rodrigues and Beldade, 2020). For example, warmer temperatures can increase estivation (dormant physiological state that takes place in summer in response to high temperatures), lead to earlier emergence from diapause (hormonally mediated delay in development in response to adverse environmental conditions) and/or advanced phenology (e.g., Saulich and Musolin, 2017; Davies, 2019; Marshall et al., 2020). Moreover, the associated lengthening of the active season enable many insect groups to complete more generations (voltinism) (e.g., Jönsson et al., 2009; Altermatt, 2010; Martín-Vertedor et al., 2010). Such changes can trigger multiple impacts on antagonistic interactions, such as phenological mismatches between natural enemies and their hosts 
(Damien and Tougeron, 2019; Abarca and Spahn, 2021), or the alteration of community structure and food webs (Harvey et al., 2020; Lann et al., 2021), with detrimental consequences for pest control in agricultural and forest systems (Tougeron et al., 2020; Frank, 2021; Lann et al., 2021). In specialized host-parasitoid interactions, trophic levels often respond differently to thermal stress, but in general, parasitoids will be more constrained than hosts, not only by direct phenological shifts affecting their populations, but also by indirect bottom-up and top-down effects (Chidawanyika et al., 2019; Thierry et al., 2019; Tougeron et al., 2020). Despite their ecological and economic impacts, scarce attention has been paid to potential effects on plantgall insect-parasitoid tritrophic interactions (but see Noe and Niinemets, 2020; Gil-Tapetado et al., 2021a), and further research is needed on this issue.

The chalcid parasitoid Torymus sinensis (Hymenoptera: Torymidae), native to East Asia, is an effective biological control agent of the invasive Asian chestnut gall wasp Dryocosmus kuriphilus (Hymenoptera: Cynipidae), the most serious chestnut pest worldwide (Avtzis et al., 2019; EPPO, 2021). The use of this exotic natural enemy is a good example of successful classical biological control; this is the reason why it has been introduced wherever the pest spread over the past decades (Moriya et al., 1989; Avtzis et al., 2019; Marcolin et al., 2021). The life-cycle of $T$. sinensis is highly synchronized with that of its host D. kuriphilus (T. sinensis adults emerge from 1-year-old dry galls at the end of winter, shortly after the reactivation of D. kuriphilus larvae and subsequent gall induction, and parasitize larval stages growing inside the newly formed galls) and both species have been widely reported as univoltine (Moriya et al., 1989; Murakami et al., 1995; Cooper and Rieske, 2011; Ferracini et al., 2015). Although T. sinensis was traditionally considered as host-specific, an extensive tracking over the first 10 years after its introduction in mid-northern Italy demonstrated less strict monophagy and higher phenological plasticity than previously thought (Ferracini et al., 2017; about host specificity also see Gil-Tapetado et al., 2021b).

The phenology of exotic insect species may be subject to temperature-mediated alterations in their areas of introduction, particularly in their extreme distributional ranges. The southernmost distributional range of Castanea sativa chestnuts in continental Europe occurs in the southern Spanish province of Málaga, with the warmest European growing conditions (annual mean temperatures ranging from 13.1 to $16.0^{\circ} \mathrm{C}$ ). Dryocosmus kuriphilus was first detected in 2014 in this area, and spread rapidly through the province, while $T$. sinensis has been yearly released in all affected localities since the year following the pest detection (Nieves-Aldrey et al., 2019; Wong et al., 2021). Climatic conditions in southern Spain could exert even greater selective pressure and lengthen the active period of both D. kuriphilus and T. sinensis in comparison to northern latitudes (Gil-Tapetado et al., 2021a; Quinto et al., 2021), therefore representing a suitable study area for further research into phenological shifts in T. sinensis. We predicted that bivoltinism in T. sinensis could occur in the warmest locations within the studied area, which would allow the occurrence of a first rapid life-cycle inside the newly formed fresh spring galls and likely start a second cycle on the same D. kuriphilus cohort. With this aim, we sampled fresh spring D. kuriphilus galls across different locations and further assessed the influence of temperature variables. Given that gall traits can be related to temperature regimes and may play a crucial role in this host-parasitoid interaction (Gil-Tapetado et al., 2021a,c), we also evaluated the effect of the number of chambers per gall, which in turn is a proxy for gall size (László and Tóthmérész, 2013).

\section{METHODS}

\section{Data Collection}

Around $450 \mathrm{D}$. kuriphilus fresh spring galls were collected on 11-May-2021 from each of 17 chestnut sampling locations framed in three municipalities (Igualeja, Pujerra, and Jubrique) at the foothills of the Sierra de las Nieves mountainous enclave (Málaga, Spain; Figure 1A). Within each sampling location, leaf, bract, and basal galls were randomly collected from 8 to 10 trees, which were detached from shoots, and the leaf tissues cleaned. Twenty galls per sampling location were dissected and the mean number of chambers/gall (mean \pm SD: $4.81 \pm 1.01$ chambers/gall; range: 3.45-6.85) and of immature pre-dormant $T$. sinensis individuals per sampling location were determined. The estimation of immature $T$. sinensis individuals allowed to quantify the average parasitism by $T$. sinensis with a presumably univoltine life-cycle per sampling location:

univoltine $T$. sinensis parasitism (\%) =

$$
\frac{\text { number of immature } T \text {. sinensis individuals }}{\text { number of dissected galls } \mathrm{x} \text { mean number of chambers/gall }} \times 100
$$

In addition, $435.38 \pm 121.42$ (mean $\pm \mathrm{SD}$ ) fresh galls per sampling location (range: 260-691) with no previous exit holes were immediately stored in $75 \times 7.5 \mathrm{~cm}$ sterilized cardboard tubes (one per location) with extractable tubes exposed to light. Tubes were maintained in laboratory conditions under natural daylight and ambient temperature and relative humidity. They were daily monitored for parasitoid emergence until late June, when no more parasitoids emerged after 10 days. Average bivoltine parasitism (parasitism hereafter) by $T$. sinensis across locations was calculated as:

$$
\begin{gathered}
\text { bivoltine } T \text {. sinensis parasitism }(\%)= \\
\frac{\text { number of emerged } T \text {. sinensis individuals }}{\text { number of stored galls } \mathrm{x} \text { mean number of chambers/gall }} \times 100
\end{gathered}
$$

Besides, T. sinensis bivoltine/univoltine parasitism ratio per sampling location was calculated. The identity of immature and emerged T. sinensis individuals was corroborated using the keys provided by Nieves-Aldrey and Gil-Tapetado (2019).

Finally, to test whether the temperature is determinant of T. sinensis bivoltinism, we obtained fine-scale spatial temperature values (annual mean temperature, annual number of days with maximum temperature $>25^{\circ} \mathrm{C}$, annual number of days 
A

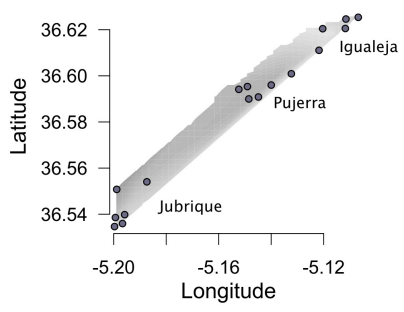

C bivoltine/univoltine parasitism by $T$. sinensis (ratio)
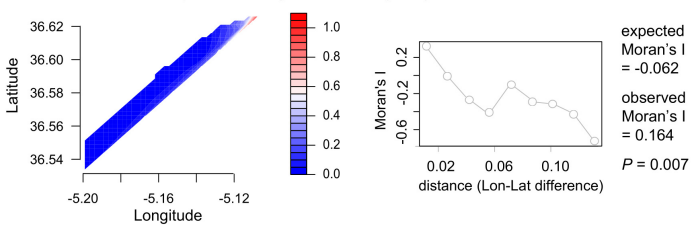

E annual mean temperature $\left({ }^{\circ} \mathrm{C}\right)$

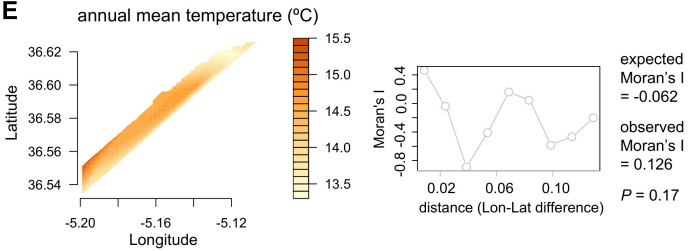

G annual days with minimum temperature $>20^{\circ} \mathrm{C}$

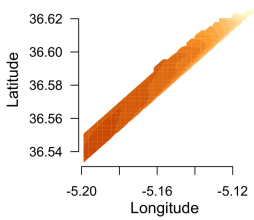

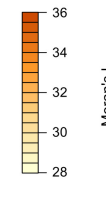

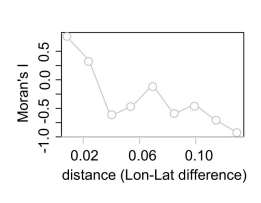

expected Moran's I
$=-0.062$

observed
Moran's I

$=0.618$

FIGURE 1 | (A) Spatial distribution of the 17 sampling locations in Málaga province, Spain. (B-H) Spatial contour plots, Moran's I statistics and correlograms for all dependent and explanatory variables.

with minimum temperature $>20^{\circ} \mathrm{C}$, and annual number of days with minimum temperature $<0^{\circ} \mathrm{C}$ ) for each of the 17 sampling locations from the 1971 to 2000 Iberian Climatic Atlas of AEMET (State Meteorological Agency of Spain), which provides georeferenced data with an accuracy of $1 \mathrm{~km}^{2}$.

\section{Statistical Analyses}

We used the statistical program $\mathrm{R}$ version 3.5 .2 for the analyses (R Core Team, 2020). First, we tested the occurrence of spatial autocorrelation for all dependent ( $T$. sinensis bivoltine/univoltine parasitism ratio and $T$. sinensis bivoltine parasitism) and explanatory variables (T. sinensis univoltine parasitism, temperature measurements, and mean D. kuriphilus chambers/gall), based on Moran's I correlation coefficient for distance matrices (Griffith and Chun, 2014; Hansen et al., 2020). Moran's I correlation coefficients were calculated with the package ape (Paradis and Schliep, 2019), and we used the package pgirmess (Giraudoux, 2021) for plotting the correlograms and
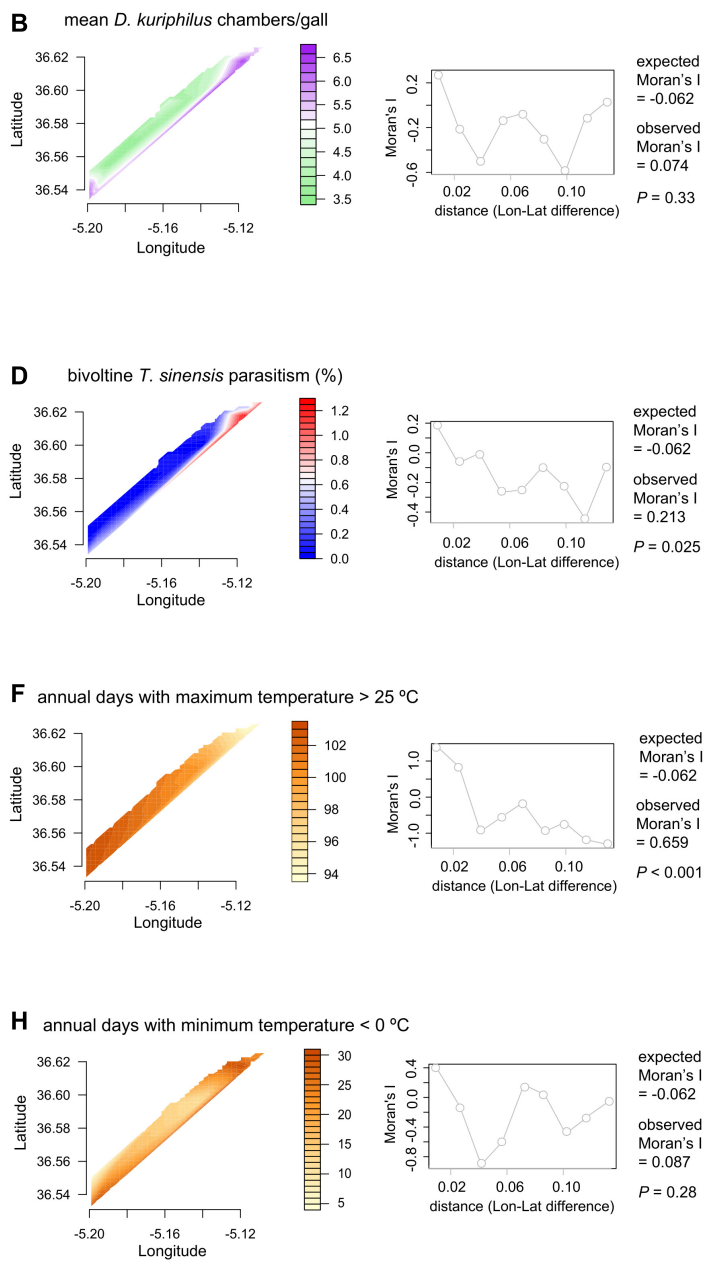

the package akima (Akima and Gebhardt, 2020) for plotting the spatial contour plots.

Next, we tested the relationship between the dependent and explanatory variables. Given the overall high spatial autocorrelation observed for both explanatory and dependent variables (higher than expected in all cases; Figures $\mathbf{1 B}-\mathbf{H}$ ), we performed spatially explicit regression models with the package spaMM (Rousset and Ferdy, 2014), set to linear or quadratic functions based on model fit (Supplementary Table 1). Regarding the different temperature measurements, we used the ones that showed the best model fit in each case (Supplementary Table 1). We used the packages ggplot2 (Wickman, 2016) and rms (Harrell, 2019) for graphing the scatterplots and 3D plots.

\section{RESULTS}

A total of $144 T$. sinensis individuals emerged from the fresh spring galls collected in May 2021. This implies a T. sinensis bivoltine parasitism of $0.34 \pm 0.41 \%$ (mean $\pm \mathrm{SD}$; range: 


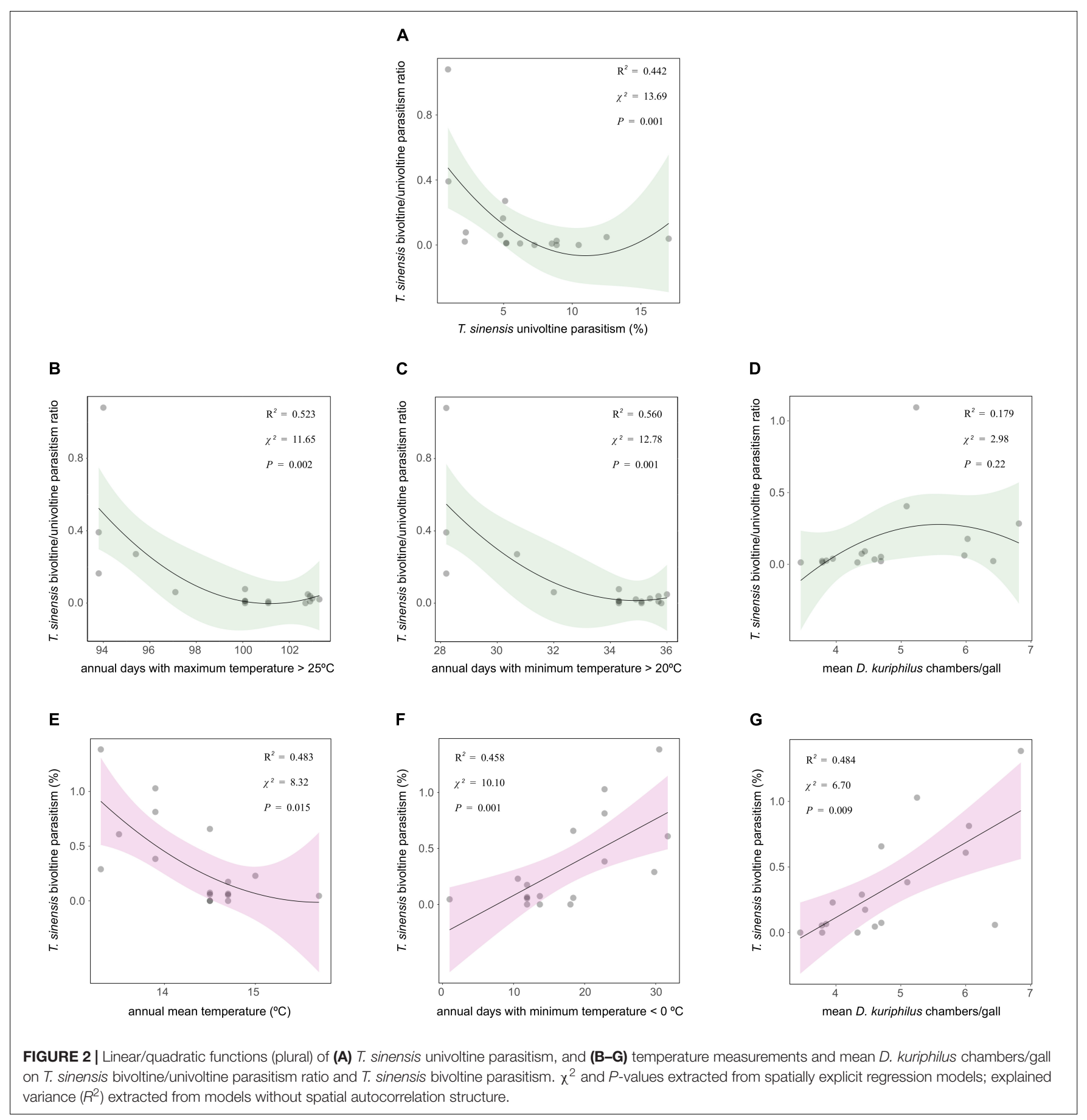

0-1.38\%). Torymus sinensis univoltine parasitism was $6.54 \pm$ $4.24 \%$ (mean \pm SD; range: $0.95-17.02 \%$ ), whereas $T$. sinensis bivoltine/univoltine parasitism ratio was $0.13 \pm 0.26$ (mean \pm SD; range: 0-1.08).

Torymus sinensis bivoltine/univoltine parasitism ratio showed a non-linear correlation with $T$. sinensis univoltine parasitism: the relationship was negative, but only when $T$. sinensis univoltine parasitism was lowest (Figure 2A). Torymus sinensis bivoltine/univoltine parasitism ratio was negatively correlated with the annual number of days with a maximum temperature $>$ $25^{\circ} \mathrm{C}$ and with a minimum temperature $>20^{\circ} \mathrm{C}$ (Figures 2B,C), whereas no significant correlation with the mean number of D. kuriphilus chambers/gall was detected (Figure 2D). Torymus sinensis bivoltine parasitism showed no correlation with T. sinensis univoltine parasitism $\left(\chi^{2}=1.78, P=0.18\right)$, whereas it was negatively correlated with annual mean temperature (Figure 2E), and conversely, positively correlated with annual days with a minimum temperature $<0^{\circ} \mathrm{C}$ and with the mean number of D. kuriphilus chambers/gall (Figures 2F,G).

Temperature patterns and D. kuriphilus chambers/gall did not show significant interactive effects on $T$. sinensis bivoltine/univoltine parasitism ratio (Figures 3A,B), but had a 

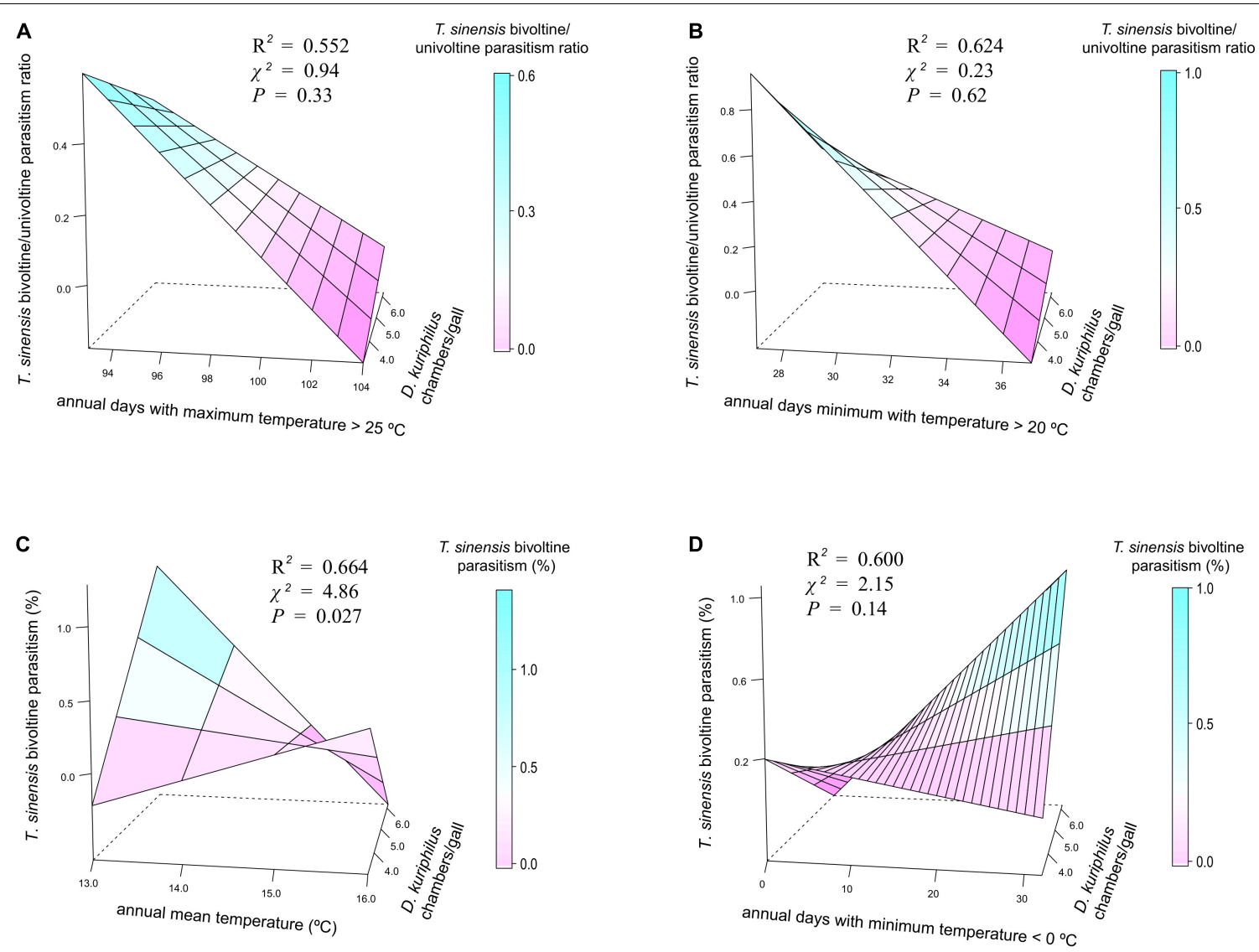

FIGURE 3 | 3D plots showing the joint effect of temperature measurements and $D$. kuriphilus chambers/gall on (A,B) T. sinensis bivoltine/univoltine parasitism ratio and (C,D) T. sinensis bivoltine parasitism. $\chi^{2}$ and $P$-values extracted from spatially explicit regression models; explained variance $\left(R^{2}\right)$ extracted from models without spatial autocorrelation structure.

synergistic interactive effect on $T$. sinensis bivoltine parasitism (Figure 3C). The highest bivoltinism rate took place in those locations in which the number of $D$. kuriphilus chambers/gall was higher $(\geq 5)$ and where the coolest annual mean temperature occurred $\left(\leq 14^{\circ} \mathrm{C}\right)$. When annual days with a minimum temperature $<0^{\circ} \mathrm{C}$ was taken as the measure of temperature, such an interactive effect was not observed (Figure 3D).

\section{DISCUSSION}

We demonstrate the occurrence of bivoltinism in the widely introduced biological control agent T. sinensis in southern Spain. A small but significant proportion of the population (mean: 13\%) was able to complete a rapid immature development in less than 3 months and emerge in May-June from fresh galls, instead of estivating in larval stage during summer and overwintering as last larval or early pupal stage (Ferracini et al., 2015; Borowiec et al., 2018).

Contrary to what we predicted, bivoltinism was favored in locations with larger galls and cooler temperatures (annual mean temperatures around $13.5^{\circ} \mathrm{C}$; Figures 2, 3). Several gall sizederived indirect effects could explain the positive relationship between large galls and bivoltinism. On the one hand, more D. kuriphilus larvae can escape from parasitism in larger galls, i.e., with more chambers (Bonsignore and Bernardo, 2018; GilTapetado et al., 2021c), which could determine higher availability of hosts for a potential second generation of T. sinensis. Gall size is also positively related with $D$. kuriphilus population densities (Kato and Hijii, 1993), since a greater number of eggs/bud are laid at higher densities, which leads to the formation of larger galls. On the other hand, larger galls could more strongly buffer the impact of abiotic factors (Price et al., 1987; Miller, et al., 2009), delaying the immature development of D. kuriphilus, thus becoming potential prey for the offspring of $T$. sinensis individuals emerging from spring galls. Further evidence supporting the effect of temperature on gall size was recently reported by Gil-Tapetado et al. (2021a), who highlighted that larger galls are formed in the Mediterranean region than in cooler conditions in the Eurosiberian region. Regarding temperatures, the offspring of those $T$. sinensis emerging from spring galls in May could be able to parasitize the same cohort of D. kuriphilus, specifically individuals remaining in L3 stage (Quinto et al., 2021). However, the duration of the immature development of $D$. kuriphilus could be shortened and the adult phenology advanced in the warmest locations, consequently 
reducing the likelihood of parasitization by a second generation of $T$. sinensis.

Several aspects raised in this study require further research. First, it should be delved into the high spatial autocorrelation observed for bivoltinism (Figure 1), which could be partially attributed to local microenvironmental conditions. Second, large-scale studies assessing the potential emergence of $T$. sinensis from fresh spring galls throughout its entire distributional range are needed to understand how thermal regimes influence on this phenomenon, including different chestnut species and genotypes. Third, the persistence of bivoltinism and its long-term ecological and evolutionary consequences for the components of this specialized plant-gall inducing host-parasitoid tritrophic interaction must be thoroughly analyzed. The existence of two generations per year a priori could lead to increased population levels (making this strategy potentially beneficial and selectable for the species) and enhanced pest control. Nevertheless, the individuals of $T$. sinensis that emerged from fresh galls were somewhat smaller than those that emerge from dry galls (personal observation). Hence, the potential consequences for the population dynamics of $T$. sinensis may be negative, since a smaller adult size is generally associated to lower fertility and ultimately fitness (temperature-size rule; Honěk, 1993; Kingsolver and Huey, 2008; Verberk et al., 2021). Additionally, intraspecific competition could limit this rapid generation (with presumably shorter ovipositor) to oviposit on unparasitized host larvae in the innermost chambers. Increased temperatures due to climate change could also reduce the occurrence of bivoltinism in this area, although it is cannot be ruled out that the competitiveness of this rapidly developing generation of $T$. sinensis may increase over the years. Lastly, the high phenological plasticity observed in this species reinforce the need to study its potential environmental risks: hybridization with native species and attack on non-target species.

Host gall size and temperature influence the ratio of bivoltinism at the southernmost European distribution of T. sinensis. Long-term and large-scale upcoming studies are needed to gain knowledge about the extent, applicability and implications of voltinism changes in this important biological control agent of $D$. kuriphilus.

\section{REFERENCES}

Abarca, M., and Spahn, R. (2021). Direct and indirect effects of altered temperature regimes and phenological mismatches on insect populations. Curr. Opin. Insect Sci. 47, 67-74. doi: 10.1016/j.cois.2021.04.008

Akima, H., and Gebhardt, A. (2020). akima: interpolation of irregularly and regularly spaced data. $R$ package version 0.6-2.1. Available online at: https://cran. r-project.org/package=akima (accessed July 20, 2021).

Altermatt, F. (2010). Climatic warming increases voltinism in european butterflies and moths. Proc. R. Soc. B Biol. Sci. 277, 1281-1287. doi: 10.1098/rspb.2009.1910

Avtzis, D. N., Melika, G., Matošević, D., and Coyle, D. R. (2019). The Asian chestnut gall wasp Dryocosmus kuriphilus: a global invader and a successful case of classical biological control. J. Pest Sci. 92, 107-115. doi: 10.1007/s10340-0181046- 1

Bonsignore, C. P., and Bernardo, U. (2018). Effects of environmental parameters on the chestnut gall wasp and its complex of indigenous parasitoids. Sci. Nat. 105, 1-14. doi: 10.1007/s00114-018-1545-1

\section{DATA AVAILABILITY STATEMENT}

The raw data supporting the conclusions of this article will be made available by the authors, without undue reservation.

\section{AUTHOR CONTRIBUTIONS}

MA analyzed the data. MA and JQ led the writing of the manuscript. All authors agreed with the last draft of the manuscript, and planned, designed, and performed the research and collected the data, and executed data interpretation.

\section{FUNDING}

This research was funded by the Junta de Andalucía (Regional Government of Andalusia, Spain) and 80\% co-financed by European Regional Development Fund (ERDF), within the ERDF Regional Operational Program for Andalusia 2014-2020 (grant no. PR.PEI.IDF2019.001).

\section{ACKNOWLEDGMENTS}

We are grateful to the chestnut orchard owners and to all our colleagues at the Laboratorio de Entomología Agrícola of IFAPA for their continuous collaboration and assistance. We also thank the editor and the reviewers for their valuable insights on the manuscript.

\section{SUPPLEMENTARY MATERIAL}

The Supplementary Material for this article can be found online at: https://www.frontiersin.org/articles/10.3389/fevo.2022. 784111/full\#supplementary-material

Borowiec, N., Thaon, M., Brancaccio, L., Cailleret, B., Ris, N., and Vercken, E. (2018). Early population dynamics in classical biological control: establishment of the exotic parasitoid Torymus sinensis and control of its target pest, the chestnut gall wasp Dryocosmus kuriphilus, in France. Entomol. Exp. Appl. 166, 367-379. doi: 10.1111/eea. 12660

Chidawanyika, F., Mudavanhu, P., and Nyamukondiwa, C. (2019). Global climate change as a driver of bottom-up and top-down factors in agricultural landscapes and the fate of host-parasitoid interactions. Front. Ecol. Evol. 7:80. doi: 10.3389/fevo.2019. 00080

Cooper, W. R., and Rieske, L. K. (2011). A native and an introduced parasitoid utilize an exotic gall-maker host. BioControl 56, 725-734. doi: 10.1007/s10526011-9350- 1

Damien, M., and Tougeron, K. (2019). Prey-predator phenological mismatch under climate change. Curr. Opin. Insect Sci. 35, 60-68. doi: 10.1016/j.cois.2019. 07.002 
Davies, W. J. (2019). Multiple temperature effects on phenology and body size in wild butterflies predict a complex response to climate change. Ecology 100:e2612. doi: 10.1002/ecy.2612

EPPO (2021). European Public Prosecutor's Office. Datasheet: Dryocosmus kuriphilus.

Ferracini, C., Ferrari, E., Pontini, M., Nova, L. K. H., Saladini, M. A., and Alma, A. (2017). Post-release evaluation of non-target effects of Torymus sinensis, the biological control agent of Dryocosmus kuriphilus in Italy. BioControl 62, 445-456. doi: 10.1007/s10526-017-9803-2

Ferracini, C., Gonella, E., Ferrari, E., Saladini, M. A., Picciau, L., Tota, F., et al. (2015). Novel insight in the life cycle of Torymus sinensis, biocontrol agent of the chestnut gall wasp. BioControl 60, 169-177. doi: 10.1007/s10526-014-9633-4

Forrest, J. R. (2016). Complex responses of insect phenology to climate change. Curr. Opin. Insect Sci. 17, 49-54. doi: 10.1016/j.cois.2016.07.002

Frank, S. D. (2021). Review of the direct and indirect effects of warming and drought on scale insect pests of forest systems. Forestry 94, 167-180. doi: 10. 1093/forestry/cpaa033

Gil-Tapetado, D., Cabrero-Sañudo, F. J., Polidori, C., Gómez, J. F., and NievesAldrey, J. L. (2021a). Climate as a possible driver of gall morphology in the chestnut pest Dryocosmus kuriphilus across Spanish invaded areas. Bull. Entomol. Res. 111, 160-173. doi: 10.1017/S0007485320000450

Gil-Tapetado, D., Durán-Montes, P., García-París, M., López-Estrada, E. K., Sánchez-Vialas, A., Jiménez-Ruiz, Y., et al. (2021b). Host specialization is ancestral in Torymus (Hymenoptera, Chalcidoidea) cynipid gall parasitoids. Zool. Scr. 00, 1-28. doi: 10.1111/zsc.12515

Gil-Tapetado, D., Castedo-Dorado, F., Nieves-Aldrey, J. L., and Lombardero, M. J. (2021c). Gall size of Dryocosmus kuriphilus limits down-regulation by native parasitoids. Biol. Invasions 23, 1157-1174. doi: 10.1007/s10530-020-02427-x

Giraudoux, P. (2021). pgirmess: spatial Analysis and Data Mining for Field Ecologists. R Package Version 1.7.0. Available online at: https://cran.r-project. org/package=pgirmess (accessed July 20, 2021).

Griffith, D., and Chun, Y. (2014). Spatial Autocorrelation and Spatial Filtering. Berlin: Springer. 1477-1507. doi: 10.1007/978-3-642-23430-9_72

Gutiérrez, D., and Wilson, R. J. (2021). Intra- and interspecific variation in the responses of insect phenology to climate. J. Anim. Ecol. 90, 248-259. doi: 10.1111/1365-2656.13348

Hansen, B. B., Grøtan, V., Herfindal, I., and Lee, A. M. (2020). The Moran effect revisited: spatial population synchrony under global warming. Ecography 43, 1591-1602. doi: 10.1111/ecog. 04962

Harrell, F. E. Jr. (2019). rms: regression Modeling Strategies. R package version 5.1-4. Available online at: https://cran.r-project.org/package=rms (accessed November 15, 2021).

Harvey, J. A., Heinen, R., Gols, R., and Thakur, M. P. (2020). Climate change-mediated temperature extremes and insects: from outbreaks to breakdowns. Glob. Chang. Biol. 26, 6685-6701. doi: 10.1111/gcb. 15377

Honěk, A. (1993). Intraspecific variation in body size and fecundity in insects: a general relationship. Oikos 66:483. doi: 10.2307/3544943

Jönsson, A. M., Appelberg, G., Harding, S., and Bärring, L. (2009). Spatio-temporal impact of climate change on the activity and voltinism of the spruce bark beetle, Ips typographus. Glob. Chang. Biol. 15, 486-499. doi: 10.1111/j.1365-2486.2008. break01742.x

Kato, K., and Hijii, N. (1993). Optimal clutch size of the chestnut gall-wasp, Dryocosmus kuriphilus Yasumatsu (Hymenoptera: cynipidae). Res. Popul. Ecol. 35, 1-14. doi: 10.1007/BF025 15640

Kingsolver, J. G., and Huey, R. B. (2008). Size, temperature, and fitness: three rules. Evol. Ecol. Res. 10, 215-268. doi: 10.7717/peerj.4512

Lann, C., Le Baaren, J. V., and Visser, B. (2021). Dealing with predictable and unpredictable temperatures in a climate change context: the case of parasitoids and their hosts. J. Exp. Biol. 224:jeb.238626. doi: 10.1242/jeb.23 8626

László, Z., and Tóthmérész, B. (2013). The enemy hypothesis: correlates of gall morphology with parasitoid attack rates in two closely related rose cynipid galls. Bull. Entomol. Res. 103, 326-335. doi: 10.1017/S0007485312000764

Marcolin, E., Pividori, M., Colombari, F., Manetti, M. C., Pelleri, F., Conedera, M., et al. (2021). Impact of the Asian gall wasp
Dryocosmus kuriphilus on the radial growth of the European chestnut Castanea sativa. J. Appl. Ecol. 58, 1212-1224. doi: 10.1111/1365-2664. 13861

Marshall, K. E., Gotthard, K., and Williams, C. M. (2020). Evolutionary impacts of winter climate change on insects. Curr. Opin. Insect Sci. 41, 54-62. doi: 10.1016/j.cois.2020.06.003

Martín-Vertedor, D., Ferrero-García, J. J., and Torres-Vila, L. M. (2010). Global warming affects phenology and voltinism of Lobesia botrana in Spain. Agric. For. Entomol. 12, 169-176. doi: 10.1111/j.1461-9563.2009.00465.x

Miller, D. G. , Ivey, C. T., and Shedd, J. D. (2009). Support for the microenvironment hypothesis for adaptive value of gall induction in the California gall wasp, Andricus quercuscalifornicus. Entomol. Exp. Appl. 132, 126-133. doi: 10.1111/j.1570-7458.2009.00880.x

Moriya, S., Inoue, K., Otake, A., Shiga, M., and Mabuchi, M. (1989). Decline of the chestnut gall wasp population, Dryocosmus kuriphilus Yasumatsu (Hymenoptera: cynipidae) after the establishment of Torymus sinensis Kamijo (Hymenoptera: torymidae). Appl. Entomol. Zool. 24, 231-233. doi: 10.1303/aez. 24.231

Murakami, Y., Ohkubo, N., Moriya, S., Gyotoku, Y., Kim, H. C., and Kim, K. J. (1995). Parasitoids of Dryocosmus kuriphilus (Hymenoptera: cynipidae) in South Korea with particular reference to ecologically different types of Torymus (Syntomaspis) sinensis (Hymenoptera: torymidae). Appl. Entomol. Zool. 30, 277-284. doi: 10.1303/aez. 30.277

Nieves-Aldrey, J. L., and Gil-Tapetado, D. (2019). Evaluación del Impacto de la Introducción en el Medio Natural de Torymus sinensis Como Organismo de Control Biológico de la Especie Dryocosmus Kuriphilus, Sobre las Poblaciones de Cinípidos y Parasitoides Nativos. Expediente: Dirección General de Calidad y Evaluación Ambiental y Medio Natural; Ministerio de Agricultura, Alimentacion y Medio Ambiente; Gobierno de España.

Nieves-Aldrey, J. L., Gil-Tapetado, D., Gavira, O. N., Boyero, J. R., Polidori, C., Lombardero, M. J., et al. (2019). Torymus sinensis Kamijo, a biocontrol agent against the invasive chestnut gall wasp Dryocosmus kuriphilus Yasumatsu in Spain: its natural dispersal from France and first data on establishment after experimental releases. For. Syst. 28, 2171-9845. doi: 10.5424/fs/201928114361

Noe, S. M., and Niinemets, Ü (2020). Impact of gall-forming insects on global BVOC emissions and climate: a perspective. Front. For. Glob. Chang 3:9. doi: $10.3389 /$ ffgc. 2020.00009

Paradis, E., and Schliep, K. (2019). Ape 5.0: an environment for modern phylogenetics and evolutionary analyses in R. Bioinformatics $35,526-528$. doi: 10.1093/bioinformatics/bty633

Price, P. W., Fernandes, G. W., and Waring, G. L. (1987). Adaptive nature of insect gall. Environ. Entomol. 16, 15-24. doi: 10.1093/ee/16.1.15

Quinto, J., Wong, M. E., Boyero, J. R., Vela, J. M., and Aguirrebengoa, M. (2021). Population dynamics and tree damage of the invasive chestnut gall wasp, Dryocosmus kuriphilus, in its southernmost European distributional range. Insects 12:900. doi: 10.3390/insects12100900

R Core Team (2020). R : a Language and Environment for Statistical Computing. Available online at: http://www.r-project.org/ (accessed July 20, 2021).

Rodrigues, Y. K., and Beldade, P. (2020). Thermal plasticity in insects' response to climate change and to multifactorial environments. Front. Ecol. Evol. 8:271. doi: $10.3389 /$ fevo. 2020.00271

Rousset, F., and Ferdy, J. B. (2014). Testing environmental and genetic effects in the presence of spatial autocorrelation. Ecography 37, 781-790. doi: 10.1111/ecog. 00566

Saulich, A. K., and Musolin, D. L. (2017). Summer diapause as a special seasonal adaptation in insects: diversity of forms, control mechanisms, and ecological importance. Entomol. Rev. 97, 1183-1212. doi: 10.1134/S00138738170 90019

Thierry, M., Hrček, J., and Lewis, O. T. (2019). Mechanisms structuring hostparasitoid networks in a global warming context: a review. Ecol. Entomol. 44, 581-592. doi: 10.1111/een.12750

Tougeron, K., Brodeur, J., Le Lann, C., and Baaren, J. (2020). How climate change affects the seasonal ecology of insect parasitoids. Ecol. Entomol. 45, 167-181. doi: 10.1111/een.12792

Verberk, W. C. E. P., Atkinson, D., Hoefnagel, K. N., Hirst, A. G., Horne, C. R., and Siepel, H. (2021). Shrinking body sizes in response 
to warming: explanations for the temperature-size rule with special emphasis on the role of oxygen. Biol. Rev. 96, 247-268. doi: 10.1111/brv. 12653

Wickman, H. (2016). ggplot2: elegant Graphics for Data Analysis. New York: Springer-Verlag.

Wong, M. E., Quinto, J., Boyero, J. R., Sánchez-Callado, F. M., Álvarez Castro, F., and Aguirrebengoa, M. (2021). Estado actual de la plaga de la avispilla del castaño Dryocosmus kuriphilus y su control biológico en Andalucía. Phytoma $326,28-34$.

Conflict of Interest: The authors declare that the research was conducted in the absence of any commercial or financial relationships that could be construed as a potential conflict of interest.
Publisher's Note: All claims expressed in this article are solely those of the authors and do not necessarily represent those of their affiliated organizations, or those of the publisher, the editors and the reviewers. Any product that may be evaluated in this article, or claim that may be made by its manufacturer, is not guaranteed or endorsed by the publisher.

Copyright (c) 2022 Aguirrebengoa, Wong, Boyero and Quinto. This is an openaccess article distributed under the terms of the Creative Commons Attribution License (CC BY). The use, distribution or reproduction in other forums is permitted, provided the original author(s) and the copyright owner(s) are credited and that the original publication in this journal is cited, in accordance with accepted academic practice. No use, distribution or reproduction is permitted which does not comply with these terms. 